\title{
Influence of Sodium Bisulfite and Lithium Bromide Solutions on the Shape Fixation of Camel Guard Hairs in Slenderization Process
}

\author{
Xueliang Xiao' ${ }^{1}$ and Jinlian $\mathrm{Hu}^{2}$ \\ ${ }^{1}$ School of Textiles and Clothing, Jiangnan University, Wuxi 214122, China \\ ${ }^{2}$ Institute of Textiles and Clothing, The Hong Kong Polytechnic University, Hung Hom, Hong Kong \\ Correspondence should be addressed to Xueliang Xiao; xiao_xueliang@163.com
}

Received 5 December 2015; Accepted 7 February 2016

Academic Editor: Sébastien Déon

Copyright (C) 2016 X. Xiao and J. Hu. This is an open access article distributed under the Creative Commons Attribution License, which permits unrestricted use, distribution, and reproduction in any medium, provided the original work is properly cited.

\begin{abstract}
Outstanding performance of natural camel hair has attracted much attention on the effective use of such specialty fiber to apparel textiles. In this paper, sodium bisulfide (SB) and lithium bromide (LB) solutions were used to process the camel guard hair before its slenderization. It is found that camel guard hair processed by SB solution shows the highest breaking elongation ( 140\%) due to the breakage of disulfide bonds (reflected by Raman spectra). LB ions result in the disruption of hair crystalline phase with slight benefit to the slenderization (determined by X-ray diffraction and differential scanning calorimetry). IR spectra indicate that hydrogen bonds of camel guard hair act as fixation switch in the programmed tensile test. It is discovered that guard hair reveals the best water-induced shape memory with $90 \%$ of stretching shape recovery, whereas the value remained to be $70 \%$ and $60 \%$ for hair processed by LB and SB solutions after breaking partial crystalline phase and disulfide cross-links separately (polymer net-points). The poorer shape memory of processed guard hair benefits its slenderization for more stable fixation of stretched length.
\end{abstract}

\section{Introduction}

Because of unique characteristics, such as good luster, softness, warmth, and natural color, camel hair fibers are the most valuable asset to modify and improve handle and appearance of the final textile product either alone or in blended form $[1,2]$. Similarly to cashmere and yak hairs, camel hair also belongs to specialty fiber and is often expensive in market due to its scarcity and luxurious texture [3]. To date, huge world demand for specialty fiber has driven research into slenderization process [4-6] of coarse wool, yak, and polar bear hair fibers, such as the successful commercialized OPTIM ${ }^{\mathrm{TM}}$ wool fibers (CSIRO) [7]. A key research topic in the process is the microstructure characterization and mechanical analysis [2] of the hair fibers along with prereduction, stretching, and optimization processes, ensuring their closer performance to natural superfine fibers.

In north China, more than 50 thousand domesticated Bactrian camels survive along the line of Inner Mongolia, Ningxia, Gansu, and Xinjiang under extreme climates. Such camels have double coated fleece consisting of guard and down hairs [8]. Growing from primary follicles, guard hairs are coarse and modulated fibers (diameter from 20 to $120 \mu \mathrm{m}$ ), forming a protective coat layer over the underlying fine down hairs (diameter less than $20 \mu \mathrm{m}$ ) $[9,10]$. Like cashmere, unique characteristics of camel down hairs attract studies of stretching potential from guard hairs, which is still a blank area in camel hair processing. We separate guard hairs into intermediate $(20 \sim 50 \mu \mathrm{m})$ and coarse $(>50 \mu \mathrm{m})$ hairs for series studies. This paper investigates the mechanical manners of coarse guard hair fiber treated by water, aqueous lithium bromide ( $\mathrm{LiBr})$, and sodium bisulfite $\left(\mathrm{NaHSO}_{3}\right)$ solutions, respectively. Previously, aqueous $\mathrm{LiBr}$ solution was reported [11] to process wools to investigate the supercontraction of wool fiber after stretching. It was found [12] that $\mathrm{LiBr}$ solution could disorder the microfibrils (crystalline phase) to reach higher entropy while matrix with covalent bonds (mainly disulfide) resists the supercontraction. On the other hand, aqueous $\mathrm{NaHSO}_{3}$ solution, acting as a reduction agent, was usually employed $[4,13]$ to cleave off disulfide bonds in matrix phase of wools. This can enhance the slippage opportunity of inter $\alpha$-helical molecule chains. Thus, 
a processing of "reduction $\rightarrow$ stretching $\rightarrow$ oxidation" of wool slenderization, corresponding to the "breakage $\rightarrow$ dislocation $\rightarrow$ rebuilding" of disulfide bonds, was reported to increase the added value of wools $[5,7,14]$. Crystalline phase and covalent cross-links of $\alpha$-keratin fibers act as key netpoints to stabilize the hair structure during stretching process. Hydrogen bonds in the matrix phase are reversible [15] when interacting with water and benefit the shape fixation of hair fiber temporarily. The investigation of crystalline phase and disulfide and hydrogen bonds along with reaction to the above solutions can provide reference perspective of either slenderization of camel guard hair or spinning of synthetic polymer by biomimicking camel hair microstructures.

\section{Materials and Experiments}

2.1. Preparation. A pack of raw camel hair fibers was provided by Sunite Right Villi Co., Inner Mongolia, China. The fiber samples in light brown were selected with diameters of more than $50 \mu \mathrm{m}$ for stretching potential exploration. The samples were first scoured using industrial wool-scouring powders followed by two rinses in distilled water, and then they were dried at $40^{\circ} \mathrm{C}$ in an oven for the following tests and characterizations.

2.2. Processing and Testing. A presensitivity study showed that $2 \mathrm{~mol} / \mathrm{L}$ of aqueous lithium bromide $(\mathrm{LiBr})$ solution gave the camel hair highest breaking strain in comparison to other concentrations of LiBr solutions. Similarly, $1.2 \mathrm{~mol} / \mathrm{L}$ of aqueous sodium bisulfite $\left(\mathrm{NaHSO}_{3}\right)$ solution also resulted in the hair with the highest breaking strain compared with other concentrations of aqueous $\mathrm{NaHSO}_{3}$ solutions. Therefore, under room temperature in this study, the selected guard hairs were soaked in distilled water, aqueous $\mathrm{LiBr}(2 \mathrm{~mol} / \mathrm{L})$, and aqueous $\mathrm{NaHSO}_{3}(1.2 \mathrm{~mol} / \mathrm{L})$ solutions for three hours, respectively. The dry guard hairs and three treated hair fibers in wet status were stretched until their breakage using Instron-5566, the extension rate was set as $5 \mathrm{~mm} / \mathrm{min}$, and guard hair fiber with the largest breaking elongation was further pretreated by corresponding solution with median distribution of concentrations for tensile investigation. The relationships of load and tensile strain, load (modulus) and testing duration, and tensile strain and fiber diameter were recorded, respectively.

Furthermore, the pretreated coarse camel hair fibers were given cyclic tensile tests for three or four loading circles using Instron-5566 in a tensile strain range from 0 to $10 \%$. The shape recovery ratios of soaked hair fibers were analyzed from the configuration of cyclic tensile curves.

2.3. Characterizations. The surface topography and cross section morphologies of coarse guard fibers at dry and treated statuses (water, $\mathrm{LiBr}$, and $\mathrm{NaHSO}_{3}$ ) were gold-coated and observed using a scanning electron microscope (SEM, JEOL Model JSM-6490). An optical microscope (Nikon optiphotPOL) equipped with birefringence lenses was employed for fiber diameter measurement and regularity characterization of fiber internal macromolecules in crystalline phase. Over stretching process, the chemical functional groups and cross-links of hair fibers were examined using Fourier Transform Infrared Spectroscopy (PerkinElmer Spectrum 100 FTIR Spectrometer, USA) in the range of $3500 \sim 650 \mathrm{~cm}^{-1}$ using ATR (Attenuated-Total-Reflectance) method. The absorption spectra were recorded with four scans with a resolution of $16 \mathrm{~cm}^{-1}$. The angle $(\phi)$ of incidence light was adjusted to $39^{\circ}$, ATR crystal was diamond (refractive index $n_{1}$ is 2.4 ), and the refractive index of hair fiber $\left(n_{2}\right)$ is around 1.5. According to formula (1), the characterized depth of penetration $\left(d_{p}\right)$ is in the range of $1 \sim 15 \mu \mathrm{m}$ :

$$
d_{p}=\frac{\lambda}{2 \pi\left(n_{1}^{2}(\sin \phi)^{2}-n_{2}^{2}\right)^{1 / 2}} .
$$

Here, $\lambda$ is the wavelength of light. Raman spectra yield a set of similar but complementary information to Infrared Spectroscopy. It relies on Raman scattering from a laser in the near infrared range. The light interacts with molecular vibrations, resulting in the energy of the laser photons being shifted up and down. The chemical cross-links such as disulfide bond of hair fibers during stretching were characterized by a Horiba Jobin Yvon HR800 Raman spectrometer, which was equipped with an Ar laser $(\lambda=448 \mathrm{~nm}, 180 \mathrm{~mW})$ as the excitation light source, and an Olympus BX41 microscope. The variation of crystalline phase of coarse camel hair fiber before and after treatments can be characterized by X-ray diffraction due to the Bragg regular arrangement of crystals, which were determined by Rigaku Smart Lab XRD system ( $9 \mathrm{KW}$ ) that is equipped with $\mathrm{Cu} \mathrm{K} \alpha$ radiation with a wavelength of $1.54 \AA$. The camel hair fibers were minced in the format of short chips (powder) to cover the test stage. The test $2 \theta$ range is from $5^{\circ}$ to $40^{\circ}$ and recorded at a scan speed of $10^{\circ} \cdot \mathrm{min}^{-1}$ at $40 \mathrm{kV}$ and $40 \mathrm{~mA}$ conditions.

\section{Results and Discussions}

3.1. Single Tensile of Camel Guard Hair. Four guard hair fibers, in conditions of being dry and wet soaked in water, lithium bromide, and sodium bisulfite solutions, were conducted for single tensile tests. Figures 1(a) and 1(c) reveal the single tensile tests until breakage and up to $10 \%$ strain, respectively. For each tensile trace in Figure 1(a), a typical load-strain curve of guard hair fiber is found to exhibit three distinct, approximately linear regions, that is, Hookean, yield, and postyield. In the Hookean region, the load occurs linearly with a rapid rise in the strain from 0 to around $4 \%$. Beyond $4 \%$ strain, the fiber begins to yield, and this continues to around $20 \%$. This process of yielding requires only a very small amount of additional load. In this region, it has been considered that the $\alpha$-helices begin to unfold and transform into the $\beta$-pleated sheets. At around $20 \%$ extension, the load in the fiber begins to rise remarkably with the increase of strain. This has been interpreted as the deformation of $\beta$ pleated sheet crystals [4]. Once the strain value is greater than the end of yielding, permanent slenderization and damage to the fiber might occur.

Figure 1(c) shows the similar tensile traces with firstly increasing modulus to the maximum value at the beginning of yielding, then followed with the dropping modulus 


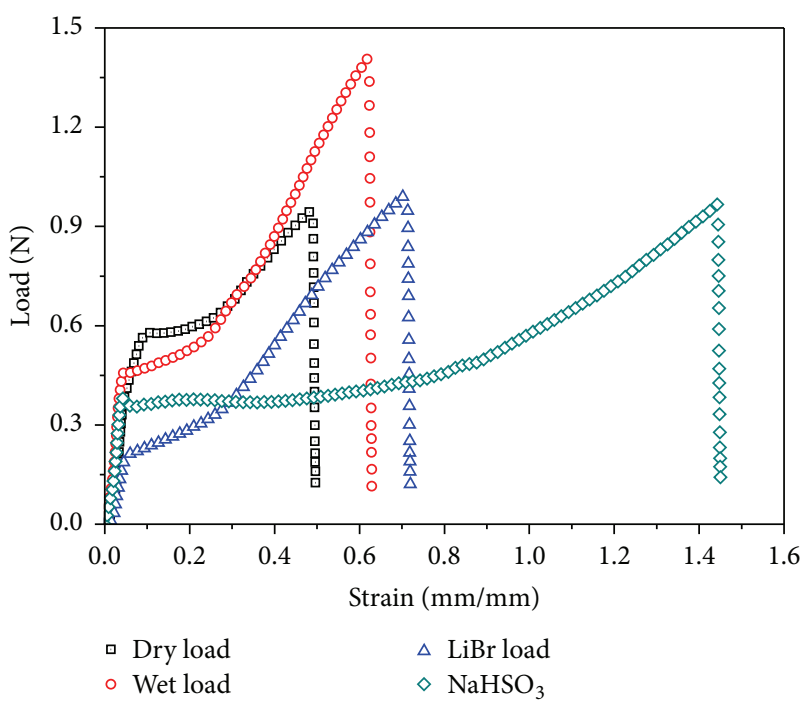

(a)

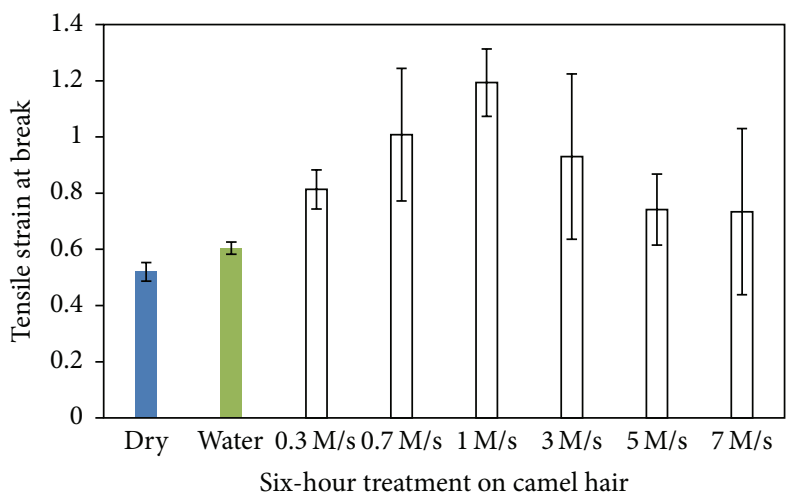

(b)

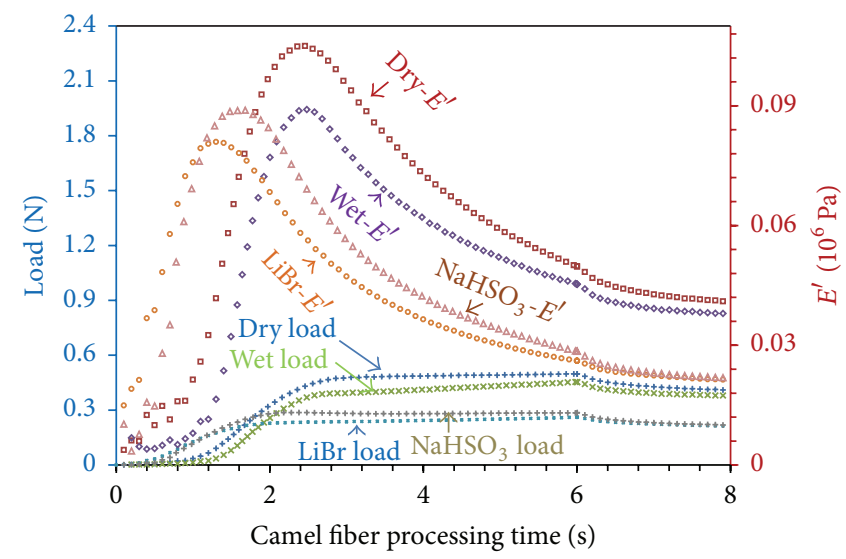

(c)

FIGURE 1: Effects of water, $\mathrm{LiBr}$, and $\mathrm{NaHSO}_{3}$ solutions on the tensile performance of camel hair fiber. (a) Load-strain relationship of hair stretching until breakage, (b) hair diameter variation at breakage, and (c) load and modulus variation of hairs in terms of stretching duration.

along the entire postyield region. The increased modulus in Hookean region is mainly due to the reorientation of molecules at matrix phase. When the stretching jaws stay at the $10 \%$ strain (yielding region), the measured stretching force and modulus are decreasing gradually. This might be ascribed to the relaxation of $\alpha$-helices during transformation. Compared with the tension of dry camel hair, Figure 1(a) shows that water and lithium bromide solution can increase the breaking elongation of camel hair slightly, whereas sodium bisulfite solution results in the largest breaking strain (more than 140\%). As a result of reduction, sodium bisulfite solution disrupts the disulfide cross-links among polypeptide chains in amorphous area, causing easier slippage of macromolecular chains and larger breaking elongation in stretching, as shown in Scheme 1.

Figure 1(b) displays the breaking strains with the concentration variation of sodium bisulfite solutions. It is found that a concentration of $1.2 \mathrm{M}$ of $\mathrm{NaHSO}_{3}$ solution leads to the hair fiber with the largest breaking strain. A larger concentration of $\mathrm{NaHSO}_{3}$ solution gives lower breaking strain due to the overly damaged disulfide bonds in partial segments of hair fiber. Table 1 lists the slenderized degree (reflected by diameter ratio) of camel guard hair at three strains after being soaked in water, lithium bromide, and sodium bisulfite solutions. Definitely, a finer hair fiber is obtained with the increase of tensile strain. As hair fiber in $\mathrm{NaHSO}_{3}$ solution has the largest tensile strain, around $50 \%$ of diametral slenderization is obtained when the tensile strain reaches $90 \%$. This slenderization potential encourages the stretching exploration from intermediate coarse hairs into down hair fibers. The positive Poisson's ratio of hair fiber during stretching in Table 1 implies the inhomogeneous (porous) structure of guard hair fibers.

Being consistent with the measured Poisson's ratios for the fiber hollow structures, Figure 2 shows the topography of camel guard hairs after three treatments. A thin layer of cover scales, a main body of cortex, and a centre porous medulla form a camel guard hair (Figure 2(a)). The porous medulla is beneficial to the hair warmth retention since still air can be stored inside the hair. Soaking in water for a certain period 


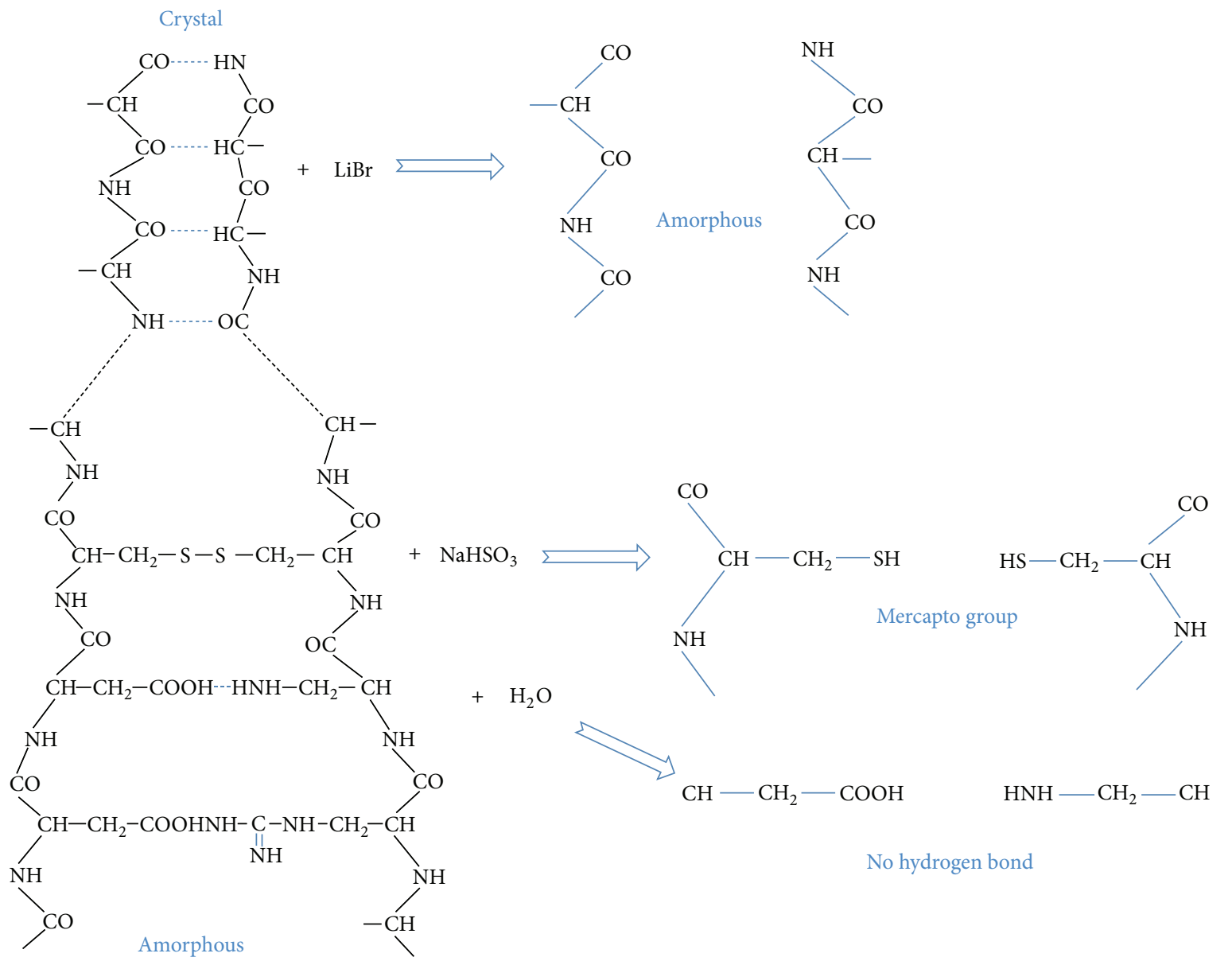

SCHEME 1

TABLE 1: Variation of hair diameter along tensile strains.

\begin{tabular}{lccc}
\hline & Strain $(\mathrm{mm} / \mathrm{mm})$ & $d^{\prime} / d$ & Poisson's ratio \\
\hline \multirow{3}{*}{ Water } & 0.15 & 0.86 & 0.93 \\
& 0.30 & 0.78 & 0.73 \\
& 0.68 & 0.70 & 0.44 \\
\hline \multirow{2}{*}{$\mathrm{LiBr}$} & 0.30 & 0.87 & 0.43 \\
& 0.60 & 0.74 & 0.43 \\
\hline \multirow{2}{*}{$\mathrm{NaHSO}_{3}$} & 0.30 & 0.90 & 0.33 \\
& 0.60 & 0.75 & 0.42 \\
& 0.90 & 0.53 & 0.52 \\
\hline
\end{tabular}

Note: $d^{\prime}$ is transient diameter and $d$ is original diameter.

can expand the volume of hair cortex, showing diametral swelling. Hair soaked in $\mathrm{LiBr}$ solution shows more separate macrofibrils (Figure 2(c)) and in $\mathrm{NaHSO}_{3}$ solution shows mud-like cortex texture (Figure 2(d)). Figure 2(e) shows the apparent macrofibrils in cortex after hair soaked in LiBr solution, where the fillers between macrofibrils are matrix phase. The macrofibrils orientate well along the fiber axis. The cuticle is a rather thin layer covering the macrofibrils. Figure 2(f) shows the longitudinal contraction of guard hair fiber after being soaked in three solutions. Unlike the supercontraction of spider silk encountered with water $[16,17]$, the contraction of camel hairs in longitudinal direction is noted to be negligible, which may be due to the large amount of residue chemical cross-linkage of macromolecules in diametral direction.

Figure 3(a) shows the smoothed XRD characteristic traces of guard hairs under four statuses. A broad characteristic peak (the black curve in Figure 3(a)) is noted for the dry camel hair that the $\alpha$-helix structural crystal manifested appearing at $2 \theta=9^{\circ}(0.98 \mathrm{~nm})$, and the $\beta$-keratin structural crystal is shown at the weak peak at $2 \theta=12^{\circ}(0.90 \mathrm{~nm})$. The $\beta$-keratin structural crystal disappears when the hair encountered with water for the reason of $\beta$-chain contraction. The $\alpha$-helix structural crystal is weakened after the hair soaked in solutions. The $\mathrm{LiBr}$ ions can disorder the margin of $\alpha$-helical crystalline phase, causing the part of $\alpha$-helical crystals irregularity, as shown in the minimum intensity of $\alpha$-helical crystals treated by LiBr. The guard hairs in four statuses were also characterized using Raman spectra, as shown in Figures 3(b) and 3(c). The peaks appearing at $550 \mathrm{~cm}^{-1}$ indicate the disulfide cross-links of guard hairs; the decrease of peak intensity indicates the disruption of S$\mathrm{S}$ bonding, especially for hair fibers processed by $\mathrm{NaHSO}_{3}$ solution. The characteristic peaks at 1170 and $1280 \mathrm{~cm}^{-1}$ show the hair Amide III structure for disordered $\alpha$-helices and 


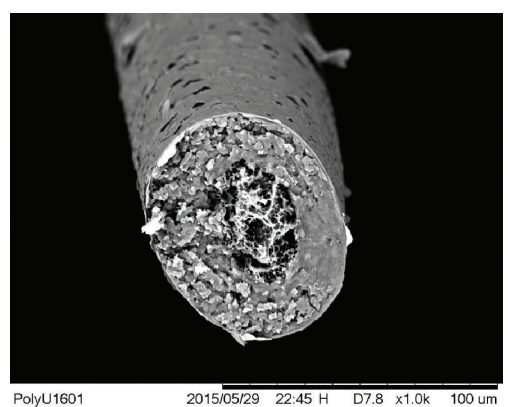

(a)

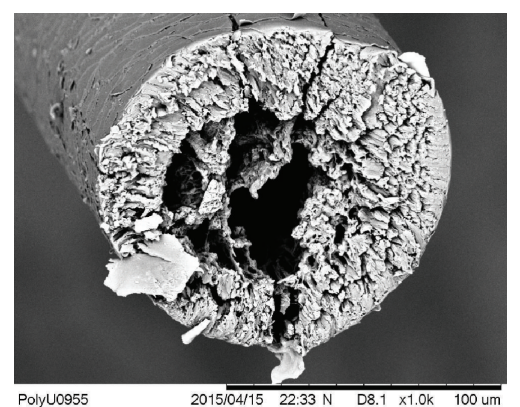

(b)

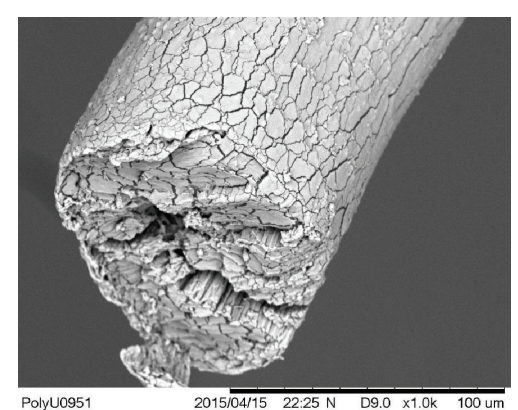

(c)

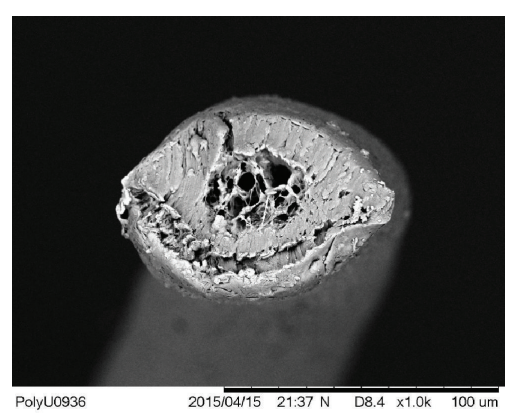

(d)

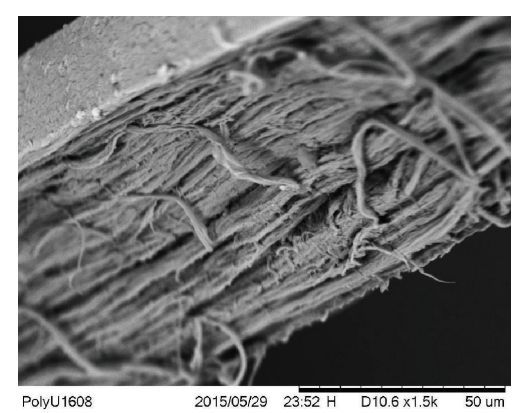

(e)

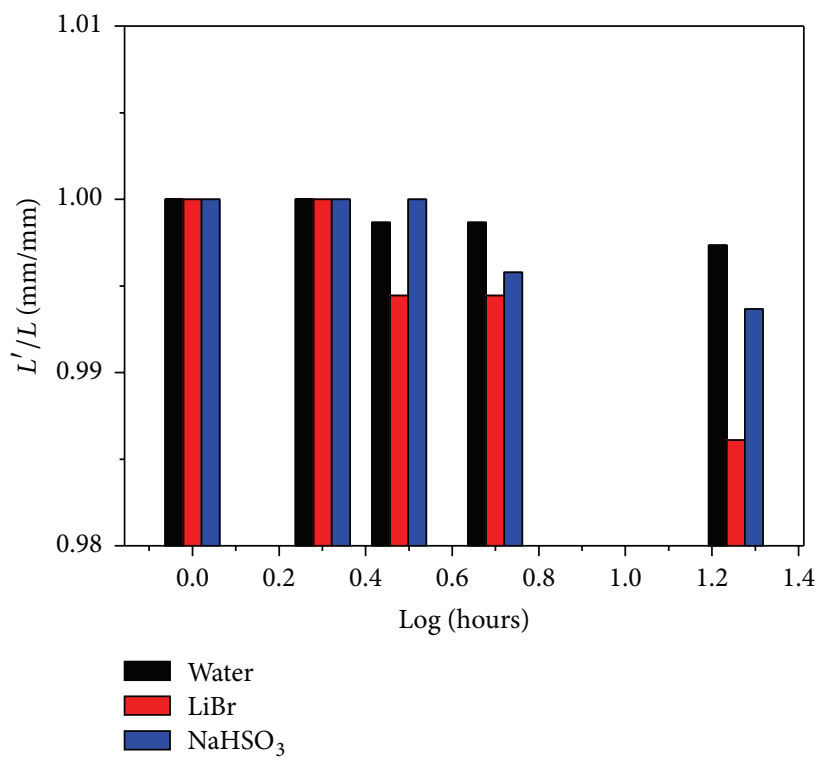

(f)

Figure 2: Cross section of camel guard hair at conditions of being (a) dry and soaked in (b) water, (c) $\mathrm{LiBr}$, and (d) $\mathrm{NaHSO}_{3}$ solutions; (e) fibrils topography at cortex; and (f) hair longitudinal contraction under duration of different processes.

partial $\beta$-pleated sheets at $1580 \mathrm{~cm}^{-1}$ show the Amide I structure for mainly $\beta$-pleated sheets and partial $\alpha$-helices and $\mathrm{CO}-\mathrm{NH}_{2}$ groups. The Raman characteristic bands and corresponding assignments for camel guard hairs are listed in Table 2. Figure 3(c) compares the Raman spectra of guard hair soaked in three concentrations of $\mathrm{NaHSO}_{3}$ solutions. The relative lower intensity of disulfide bonds of camel hair processed by $1.2 \mathrm{M}(\mathrm{mol} / \mathrm{L})$ concentration of solution indicates the less number of disulfide bonds to constrain the mobility of macromolecules for longer elongation of hair fiber in stretching. This is consistent with the stretching data as shown in Figure 1(b).

A regular intense array of macromolecules (crystalline phase) can refract a bright shining spot according to Bragg's law while disordered amorphous area with irregular molecules gives dark background under microscope due to light-wave phase cancellation. Figure 4 shows the images of four guard hairs under birefringence microscope. Dry hair fiber shows intense apparent shining spots under birefringence along fiber axis, indicating the discontinuous 


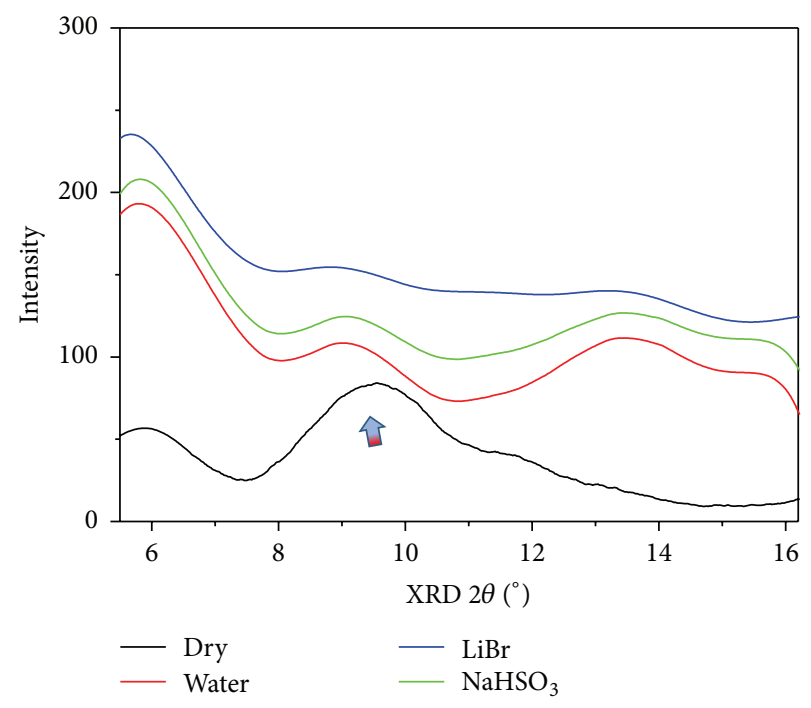

(a)

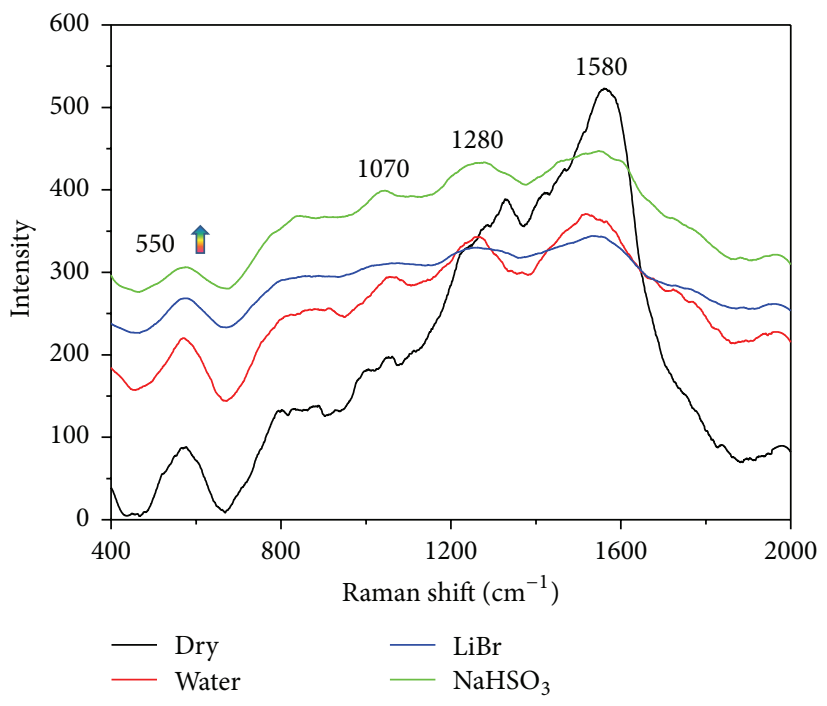

(b)

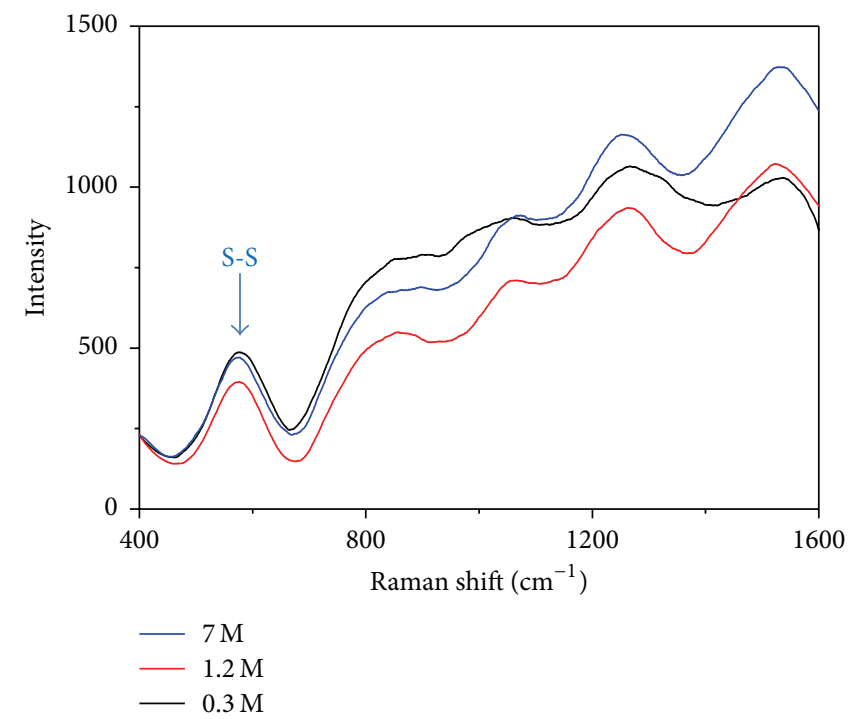

(c)

FIGURE 3: Characterizations of camel guard hairs under conditions of dry, water-soaked, $\mathrm{LiBr}(2.0 \mathrm{M})$ treated, and $\mathrm{NaHSO}_{3}$ (1.2 M) treated states using (a) XRD and (b) Raman; (c) Raman spectra for camel hair under three $\mathrm{NaHSO}_{3}$ concentrations.

TABLE 2: Raman characteristic bands and their assignments.

\begin{tabular}{|c|c|c|}
\hline Amide band & $\begin{array}{c}\text { Band position } \\
\left(\mathrm{cm}^{-1}\right)\end{array}$ & Band assignment \\
\hline Amide I & $1500 \sim 1600$ & $\begin{array}{c}\beta \text {-Pleated sheet, } \\
\alpha \text {-helix, CO-NH }\end{array}$ \\
\hline Amide III & $1000 \sim 1350$ & $\begin{array}{c}\alpha \text {-Helix, } \\
\text { disordered, } \\
\beta \text {-pleated sheet }\end{array}$ \\
\hline$-\mathrm{C}-\mathrm{C}-$ & $800 \sim 950$ & $\alpha$-Helix \\
\hline -S-S- & $500 \sim 600$ & -S-S- \\
\hline -C-S- & $600 \sim 650$ & -C-S- \\
\hline
\end{tabular}

crystalline phase of hair fiber. When guard hair fiber soaked in water, especially after hair fiber was treated by $\mathrm{LiBr}$ solution, the amount of crystalline bright spots decreases remarkably, reflected by the looser density of spots along the fiber axis. This is consistent with the XRD characterization results.

3.2. Cyclic Tensile of Camel Guard Hair. Figure 5(a) illustrates a cyclic stretching program; that is, a force is given to a native sample for stretching ending at 0.10 of strain $(1 \rightarrow$ $2 \rightarrow 3$ ) in which step 2 means the sample is in wet status; then, the stretched sample is dried for ten minutes (4) and the gauge length is returned to the native length (5) for the next step of immersing it in water (6) aiming to shape recovery (7). As can be seen from the water effect on shape recovery of camel hair, five distinct phases $\left(a^{\prime}\right.$ to $\left.e^{\prime}\right)$ are noted for each stretching cycle. Phase $a^{\prime}$ means the elastic tensile of camel hair and this also occurs at the 2nd and 

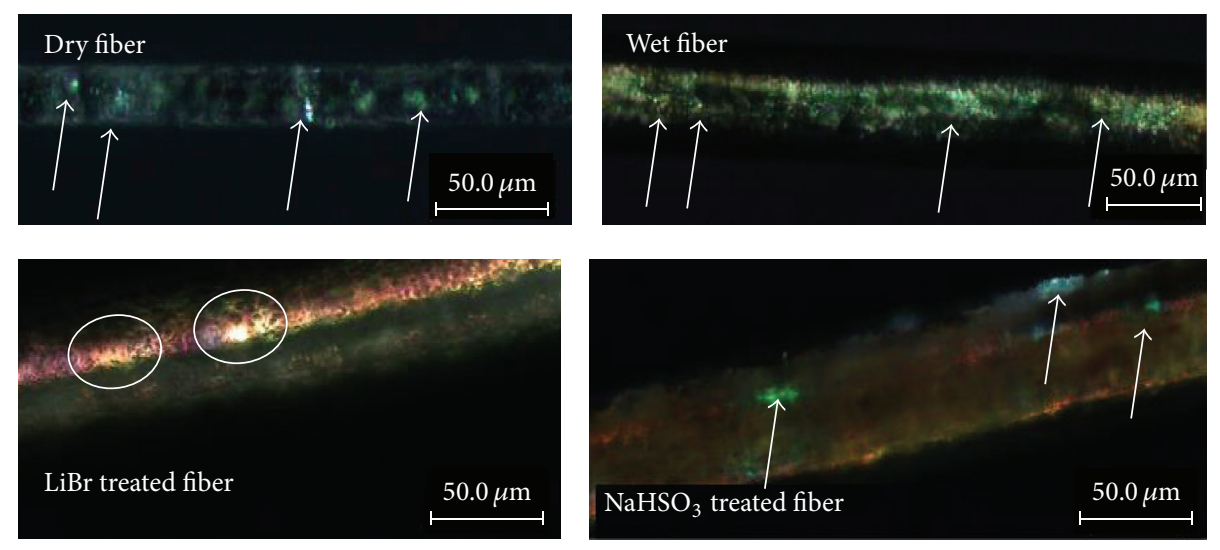

FIGURE 4: Crystalline phase characterization of camel guard hair using microscope birefringence.

3rd tensile curves. Hair stretching in this elastic strain can return to the hair native length completely, which echoes phase $d^{\prime}$ of instant strain recovery. It is found that water and aqueous $\mathrm{NaHSO}_{3}$ solution cause the identical instant shape recovery $(0.015$, i.e., $0.10-0.085)$, indicating intact crystalline phase after being treated by these solutions. Owing to the damage to the margin of hair crystal [12] by $\mathrm{LiBr}$ ions, the instant recovery of strain is increased to 0.07 , leaving merely 0.03 of shape strain recovered. The yielding phase $b^{\prime}$ resulted from the transformation of $\alpha$-helical to $\beta$-pleated conformations [4]. A slight additional load is required for the transformation. The strain due to the transformation can be recovered when the $\beta$-pleated conformation of proteins encountered with aqueous molecules, which corresponds to the shape recovery of phase $e^{\prime}$. This was supercontraction reported for spider silk and wool $[16,18]$. The unrecovered strain (around 0.01) is due to the irreversible damage to the disulfide bonds. In comparison of interaction with water, $\mathrm{LiBr}$ solution gives the guard hair rise to equal irreversible strain, whereas the $\mathrm{NaHSO}_{3}$ solution results in the maximum value of irreversible strain of 0.03 , indicating that the reduction occurred to the disulfide cross-links of hair. Moreover, the maximum load on the hair reduces remarkably after the first stretching, indicating the occurrence of slippage of intermacromolecules in tensile stretching in addition to the reversible phases of $\alpha$ to $\beta$ transformation. The shape recovery ability of the hair becomes worse after reduction to disulfide cross-links, as shown in the 2 nd to 4 th cyclic tensile curves with shape recovery of strain from 0.025 which then reduced to 0.04 after the reduction in Figure 5(d).

The characteristic peaks from IR spectra corresponding to the effect of water on the dry camel hair are shown in Figures 6 and 7. The peaks located at $3279 \mathrm{~cm}^{-1}$ and $2931 \mathrm{~cm}^{-1}$ represent the stretching vibration of $\mathrm{N}-\mathrm{H}$ and $\mathrm{C}-\mathrm{H}$ groups. The characteristic peak at $1620 \sim 1630 \mathrm{~cm}^{-1}$ is assigned to the elastic vibration peak of $\mathrm{C}=\mathrm{O}$ bond (Amide band $\mathrm{I}$ ), and the peak at $1510 \sim 1520 \mathrm{~cm}^{-1}$ is labeled as the main bending vibration peak of C-N-H bond (Amide band II) [19]. The peaks at $1448 \sim 1455 \mathrm{~cm}^{-1}$ and $1385 \sim 1390 \mathrm{~cm}^{-1}$ are stretching vibration of carboxyl (C-O) group and backbone (C-C) group. The absorption peaks at $1235 \sim 1240 \mathrm{~cm}^{-1}$ and $1070 \sim 1040 \mathrm{~cm}^{-1}$ are
TABLE 3: IR peak wave numbers of Amide bands I and II for camel hair fiber treated by $\mathrm{LiBr}$ and $\mathrm{NaHSO}_{3}$ solutions along with shape memory program steps.

\begin{tabular}{lccc}
\hline Processing of hair & Step & \multicolumn{2}{c}{ FT-IR wave number $\left(\mathrm{cm}^{-1}\right)$} \\
\hline & 1 & 1629 & 1523 \\
$\mathrm{LiBr}$ (2.0 M, 1 day) & 2 & 1633 & 1529 \\
& 3 & 1634 & 1544 \\
& 4 & 1631 & 1538 \\
& 6 & 1634 & 1508 \\
\hline & 1 & 1629 & 1523 \\
NaHSO$_{3}$ (1.2 M, 1 day) & 2 & 1633 & 1526 \\
& 3 & 1627 & 1525 \\
& 4 & 1630 & 1527 \\
& 6 & 1634 & 1521
\end{tabular}

stretching vibration of carboxyl $(\mathrm{C}=\mathrm{O})$ group and Amide $(\mathrm{C}$ $\mathrm{N})$ group (Amide band III). The penetration and removal of water molecules into and out of hair fiber in a stretching circle can move towards lower or higher IR peak abscissa of corresponding groups slightly. According to the cycle tensile steps in Figure 5(a), step "1" means a dry hair sample clamped by two grippers with an original length, step " 2 " means the clamped hair soaked in water, that is, the penetration of water molecules into hair body, and step " 3 " means that the clamped sample in wet status is stretched to a certain strain. From the viewpoint of IR peaks, take Amide bands I and II, for example; the position of two bands moves to higher value of wave number at step "2." Step "3" with further higher wave number is due to the stretching process to the wet guard hair. A drying process to the stretched wet hair sample (step "4") results in the decreased wave numbers of both bands because of the regenerated hydrogen bonds. Encountering with water (step "6") causes the shape recovery (phase $e^{\prime}$ ) of hair fiber with Amide band I and Amide band II to higher and lower IR peaks of wave numbers, respectively.

In comparison of the IR spectra of water-treated camel hair, as shown in Table 3, $\mathrm{LiBr}$ and $\mathrm{NaHSO}_{3}$ solutions cause the same tendency from steps " 1 " to " 2 " for Amide bands I and 


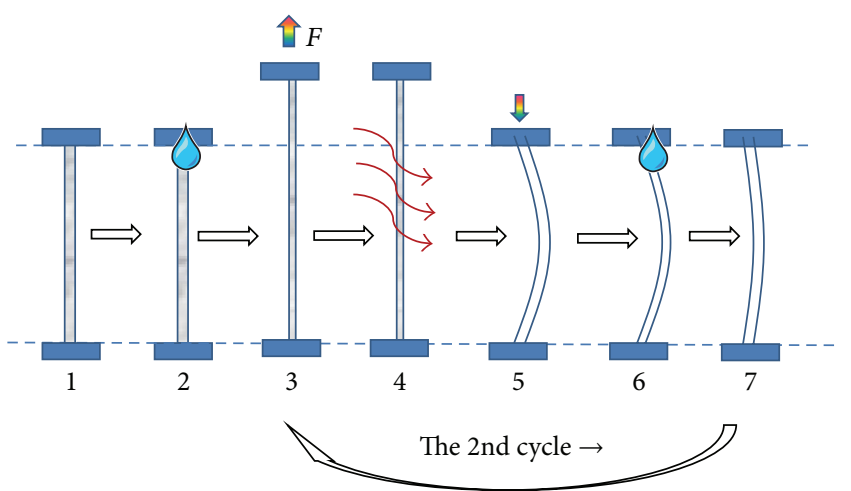

(a)

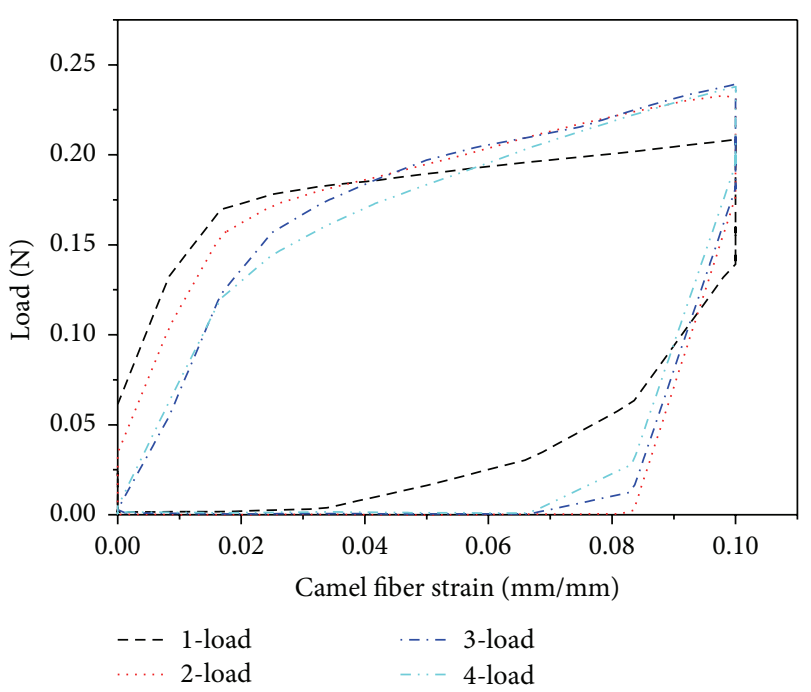

(c)

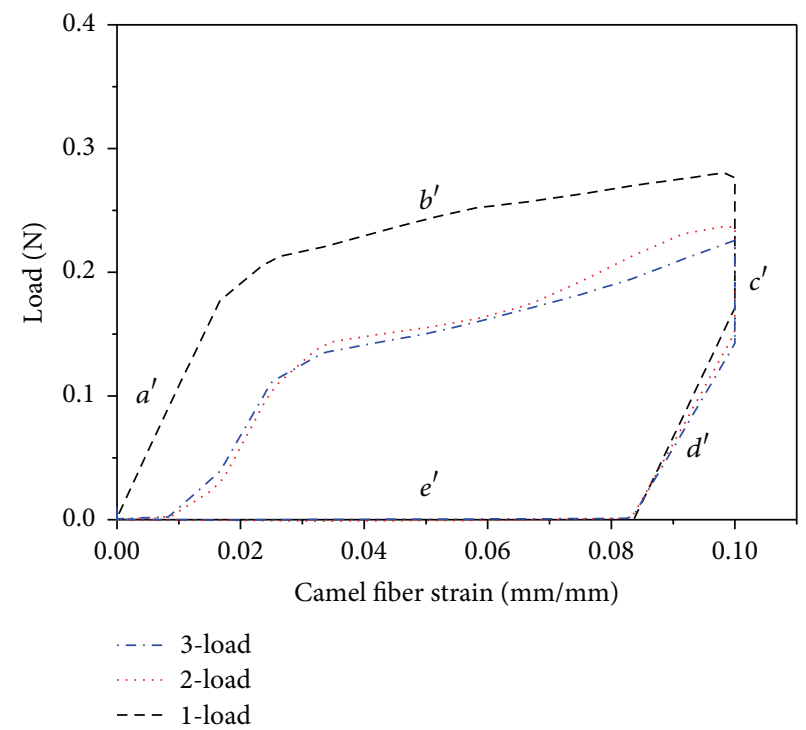

(b)

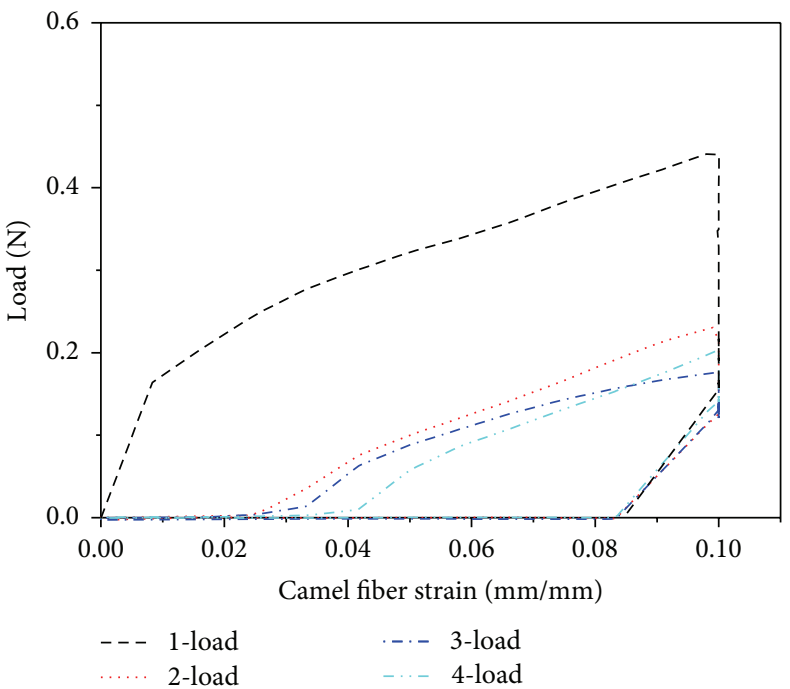

(d)

Figure 5: Cyclic tensile test of camel guard hair, (a) test program, and corresponding tensile cycles of hair samples soaked in (b) water, (c) $\mathrm{LiBr}(2 \mathrm{~mol} / \mathrm{L})$, and (d) $\mathrm{NaHSO}_{3}(1.2 \mathrm{~mol} / \mathrm{L})$ solutions.

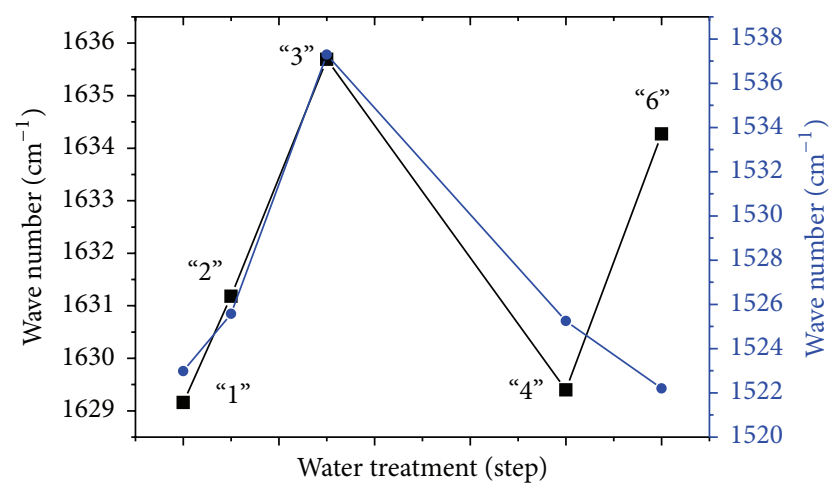

FIGURE 6: IR characteristic peaks of camel guard hair along with the water-induced shape memory program.
II. As from steps " 2 " to " 3 " and " 3 " to " 4 ," hair fiber in $\mathrm{LiBr}$ and $\mathrm{NaHSO}_{3}$ solutions displays opposite variation tendencies of peak wave numbers, whereas from steps " 4 " to " 6 ," the guard hair fibers after being soaked in $\mathrm{LiBr}$ and $\mathrm{NaHSO}_{3}$ solutions show the same change tendencies for both Amide bands. Specifically, the movement of Amide band II (C-N$\mathrm{H} \cdots \mathrm{O}=\mathrm{C}$ ) indicates the variation of hydrogen bonds. Thus, among the three processing techniques of guard hairs, it is found that the peak position from the $\mathrm{LiBr}$ treated hair moves the farthest abscissa, that is, from $1523 \mathrm{~cm}^{-1}$ to $1529 \mathrm{~cm}^{-1}$ (step "2") to $1544 \mathrm{~cm}^{-1}$ (step " 3 "). This indicates that, in addition to the hydrogen bonds at matrix phase, aqueous $\mathrm{LiBr}$ solution and stretching to guard hair also cleave off an amount of hydrogen bonds at the margin of crystalline phase. 

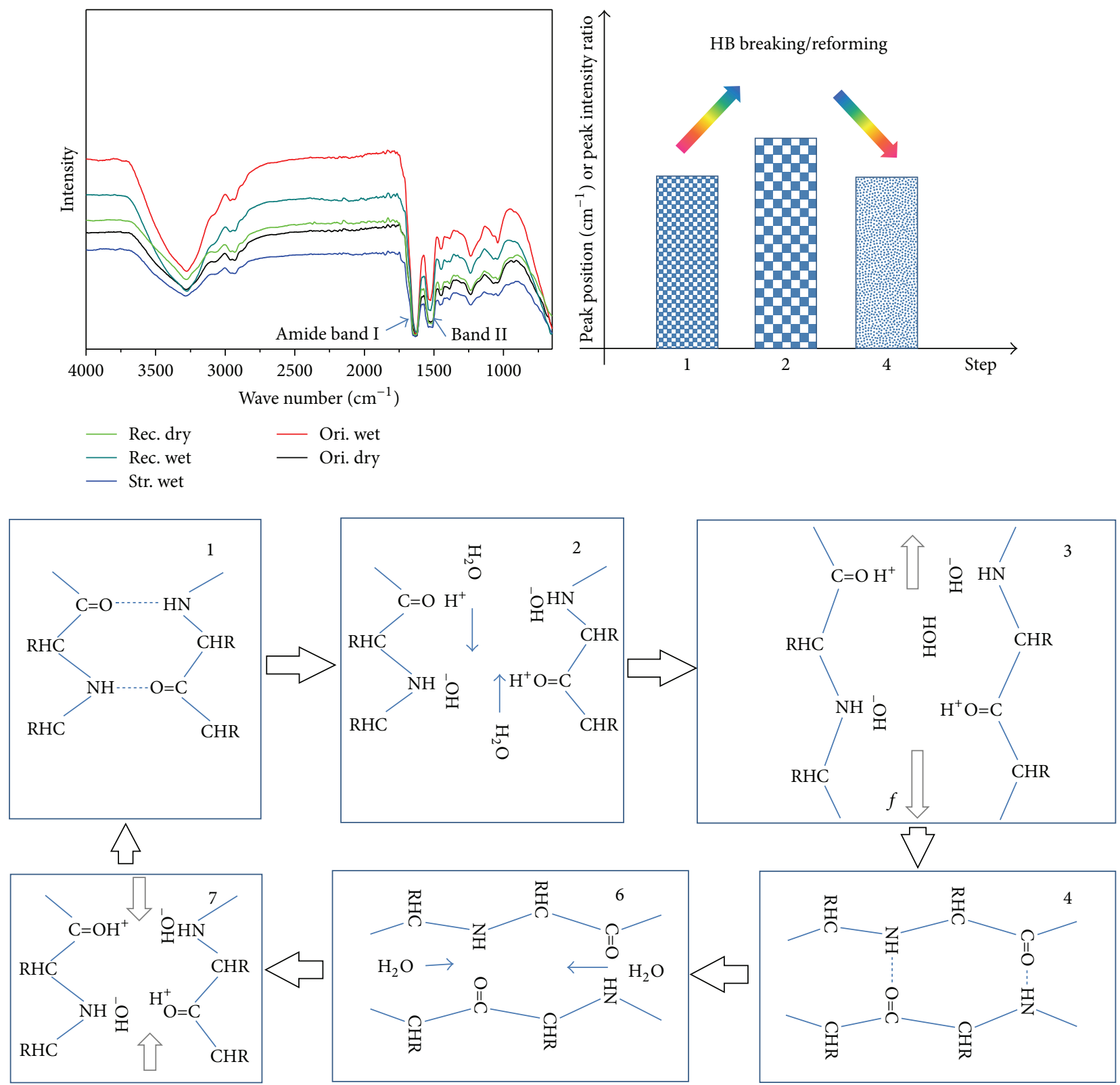

FIGURE 7: Variations of ATR-FT-IR peaks and intermolecular hydrogen bonds along with the defined SME program steps: "1": hydrogen bond between neighboring polypeptide chains under original and dry state (Ori. dry); "2": disruption of hydrogen bond by water polar molecules under original and wet state (Ori. wet); "3": stretching to water-soaked hair (Str. wet); "4": shape fixation of hair after drying process; "6": temporary shape hair encountered with water for recovery (Rec. wet); "7”: hair recovery to the original shape under dry state (Rec. dry).

Vertically, the IR peak intensity [20] can also reflect the effects of water, $\mathrm{LiBr}$, and $\mathrm{NaHSO}_{3}$ solutions on the functional groups of camel hair, as shown in the IR spectra of watertreated guard hair in a single stretching cycle in Figure 7. When the peak intensity of Amide band I $\left(1620 \sim 1630 \mathrm{~cm}^{-1}\right)$ is fixed, the relative peak intensity of Amide band II is varied in terms of program steps. The two-band intensity ratio, band II/band I, is the smallest when the guard hair soaked in water (red curve). The ratio value becomes larger when the dried hair in a temporary fixed shape encountered with water for shape recovery. The ratio values almost equal each other (largest) when the guard hair is in dry, stretched, and recovered dry statuses.
Based on the IR spectra, Figure 7 depicts the corresponding work mechanism of water on the camel guard hair according to the stretching program. Same as the tensile steps of Figure 5(a), regarding the pair steps of " 1 " and "4," the intensities of peaks at $1620 \sim 1630 \mathrm{~cm}^{-1}$ and $1510 \sim$ $1520 \mathrm{~cm}^{-1}$ are observed nearly to equal each other, indicating the approximate amount of carbonyl group $(\mathrm{C}=\mathrm{O})$ and imino group (-NH-). When the hair fiber soaked in water (step "2"), the hydrogen bonds formed between carbonyl and imino groups were cleaved by water polar molecules. The ions of $\mathrm{OH}^{-}$and $\mathrm{H}^{+}$were adsorbed, surrounded by the imino group and carbonyl group, respectively, for the cause of interactive attraction of hydrogen and oxygen ions. This leads 


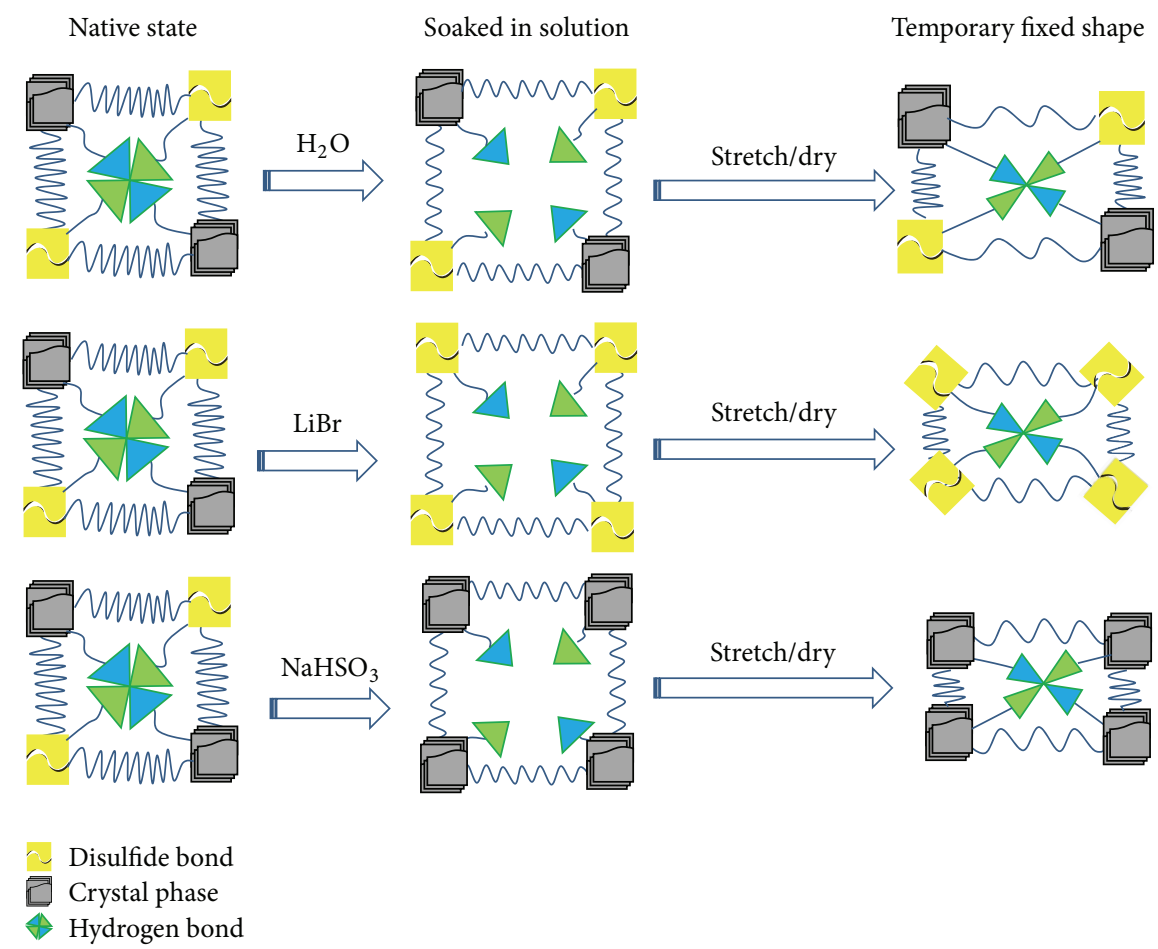

FIGURE 8: Schematic illustration of shape memory mechanism of three solutions on camel hair structure.

to the decreased number of hydrogen bonds and weakened intensity of Amide band II at 1510 1520 $\mathrm{cm}^{-1}$, as shown in the increased ratio of peak intensities of Amide band I to Amide band II (from blue curve to red curve, Figure 7).

The soaked guard hair was stretched to a certain strain, as shown in the stretched keratin backbones of step "3." The stretched wet fiber was then dried below $40^{\circ} \mathrm{C}$ (step " 4 ”) for shape fixation, giving rise to the new hydrogen bonds generated between neighboring carbonyl and imino groups. The stretched fiber becomes finer after removal of impregnated water molecules. When the dried hair fiber in stretched shape was triggered by water (step " 6 "), the generated hydrogen bonds were disrupted (step "7") again. The stretched keratin structure ( $\beta$-pleated sheet) is unstable; the residue stress of pleated backbones would release backwards its original helical structure, resulting in the shape recovery of guard hair fiber. From steps " 1 " to " 2 " and " 3 " to " 4 ," the characteristic peaks of hydrogen bonds in disruption and reformation are summarized along with the peaks of abscissa and intensity in blue motion (increased) and red motion (decreased) in Figure 7, respectively.

As a conclusion, we propose a series of simplified structure models to interpret the shape memory mechanism of three solutions on camel hair fibers, as shown in Figure 8. Since water molecules can hardly disrupt the crystalline phase and disulfide cross-links, the two components can act as twin net-points and hydrogen bonds in amorphous area act as switch unit in temporary shape fixation and recovery of guard hair. As $\mathrm{LiBr}$ and $\mathrm{NaHSO}_{3}$ solutions slightly disrupt crystalline phase and disulfide cross-links, respectively, we simplify that the camel guard hair shows single net-point structure in their shape memory effect. Due to the disruption of disulfide cross-links among protein macromolecule chains, slippage of intermolecules in the stretching may occur easily for a large elongation, giving rise to the stretched hair fiber, a poor shape recovery ability, and a good slenderization effect.

\section{Conclusions}

As a kind of specialty fiber, fine camel hair shows good warmth, softness, and luxurious texture. Its scarcity drives investigation of such hair based on its structure, mechanics, and processing. Referring to slenderization process of wool fibers, this paper studies the effects of water, aqueous lithium bromide, and sodium bisulfite solutions on camel hair properties, respectively, for slenderization potential of camel guard hair. After hair fiber soaked in the three solutions, it is found that the largest stretching elongation is from the processing of aqueous sodium bisulfite solution (1.2 M) and the diameter of hair can be half reduced after stretching to $90 \%$ of strain. The porous modulated and cortex fibrils topographies of hair show high advantage of such hair fiber in slenderization for hollow structure under high fixed stretched status.

$\mathrm{XRD}$ and birefringence characterizations indicated that water and aqueous sodium bisulfide solution have little effect on guard hair crystalline phase ( $\alpha$-helical crystal) while aqueous lithium bromide solution weakens such crystalline phase. Raman spectra showed that aqueous sodium bisulfide solution and stretching process in yielding (or after yielding) can disrupt disulfide cross-links between $\alpha$-keratin macromolecules and slippage of them. Cyclic tensile tests to guard hairs showed that camel hair is a typical shape memory material induced by water. Infrared spectra showed that Amide 
bands I and II of their peak locations move towards higher and lower wave numbers, and peak intensity ratio becomes larger and smaller when immersing in and removing water, respectively. A series of simplified geometrical models were proposed to interpret the shape memory principle of three solutions on camel guard hair. The model can assist with exploring future slenderization processing of camel guard hair for its great market adding value.

\section{Competing Interests}

The authors declare that there are no competing interests regarding the publication of this paper.

\section{Acknowledgments}

The authors would like to thank the financial support from the HK RGC Project, no. 15209815.

\section{References}

[1] A. Sharma and S. Pant, "Studies on camel hair-merino wool blended knitted fabrics," Indian Journal of Fibre and Textile Research, vol. 38, no. 3, pp. 317-319, 2013.

[2] T. Harizi, S. Msahli, F. Sakli, and T. Khorchani, "Evaluation of physical and mechanical properties of Tunisian camel hair," Journal of the Textile Institute, vol. 98, no. 1, pp. 15-21, 2007.

[3] K. D. Langley and T. A. Kennedy Jr., "The identification of specialty fibers," Textile Research Journal, vol. 51, no. 11, pp. 703709, 1981.

[4] H. L. Liu and W. D. Yu, "Microstructural transformation of wool during stretching with tensile curves," Journal of Applied Polymer Science, vol. 104, no. 2, pp. 816-822, 2007.

[5] J. Liu, Y. Weng, and W. D. Yu, "Mechanism analysis of stretching slenderization by shape and structure for coarse yak hair," in Proceedings of the 12th International Wool Research Conference (IWRC '10), Shanghai, China, October 2010.

[6] J. W. Yao and W. D. Yu, "Study on the properties and application of optim (TM) fine fibers," in Proceedings of the International Conference on Civil Engineering and Building Materials (CEBM '11), pp. 2561-2564, September 2011.

[7] Z. Motaghi, S. Eskandarnejad, and M. Montazer, "Investigation of slandering on coarse wool fiber and its characteristics," in Proceedings of the RMUTP International Conference: Textiles \& Fashion, Bangkok, Thailand, July 2012.

[8] H. R. Ansari-Renani, M. Salehi, Z. Ebadi, and S. Moradi, "Identification of hair follicle characteristics and activity of one and two humped camels," Small Ruminant Research, vol. 90, no. $1-3$, pp. 64-70, 2010.

[9] O. J. Petrie, Harvesting of Textile Animal Fibres, Food and Agricultural Organization of the United Nations, Wool Testing Authority, Wellington, New Zealand, 1995.

[10] L. Iñiguez, J. P. Mueller, A. Ombayev et al., "Characterization of camel fibers in regions of Kazakhstan and Uzbekistan," Small Ruminant Research, vol. 117, no. 1, pp. 58-65, 2014.

[11] M. Feughelman, A. R. Haly, and T. W. Mitchell, "The nature of permanent set in keratin fibers," Textile Research Journal, vol. 28, no. 8, pp. 655-659, 1958.

[12] B. M. Chapman, "Observations on the mechanical behavior of Lincoln-wool fibers supercontracted in lithium bromide solution," The Journal of the Textile Institute, vol. 61, no. 9, pp. 448-457, 1970.

[13] A. Khishigsuren, M. Nakajima, and M. Takahashi, "Effects of ferrous mordanting on bleaching of camel hair," Textile Research Journal, vol. 71, no. 6, pp. 487-494, 2001.

[14] Y. T. Zhang, W. D. Yu, S. H. Hu, and H. L. Liu, "A chemical processing on wool's stretching slenderization setting," Patent ZL.01112858.5, 2004.

[15] J. D. Eaves, J. J. Loparo, C. J. Fecko, S. T. Roberts, A. Tokmakoff, and P. L. Geissler, "Hydrogen bonds in liquid water are broken only fleetingly," Proceedings of the National Academy of Sciences of the United States of America, vol. 102, no. 37, pp. 13019-13022, 2005.

[16] S. Sampath and J. L. Yarger, "Structural hysteresis in dragline spider silks induced by supercontraction: an X-ray fiber microdiffraction study," RSC Advances, vol. 5, no. 2, pp. 1462-1473, 2015.

[17] C. Boutry and T. A. Blackledge, "Wet webs work better: humidity, supercontraction and the performance of spider orb webs," Journal of Experimental Biology, vol. 216, no. 19, pp. 36063610, 2013.

[18] W. T. Astbury and H. J. Woods, "X-ray studies of the structure of hair, wool, and related fibres. II. The molecular structure and elastic properties of hair keratin," Philosophical Transactions of the Royal Society of London. Series A, Containing Papers of a Mathematical or Physical Character, vol. 232, pp. 333-394, 1934.

[19] J. Yao, Y. Liu, S. Yang, and J. Liu, "Characterization of secondary structure transformation of stretched and slenderized wool fibers with FTIR spectra," Journal of Engineered Fibers and Fabrics, vol. 3, no. 2, p. 47, 2008.

[20] J. Shao, J. Zheng, J. Liu, and C. M. Carr, "Fourier transform Raman and Fourier transform infrared spectroscopy studies of silk fibroin," Journal of Applied Polymer Science, vol. 96, no. 6, pp. 1999-2004, 2005. 


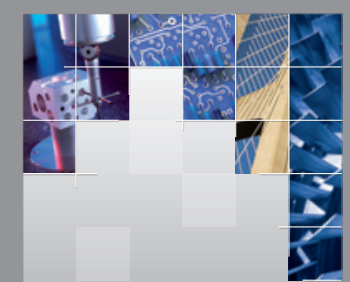

\section{Enfincering}
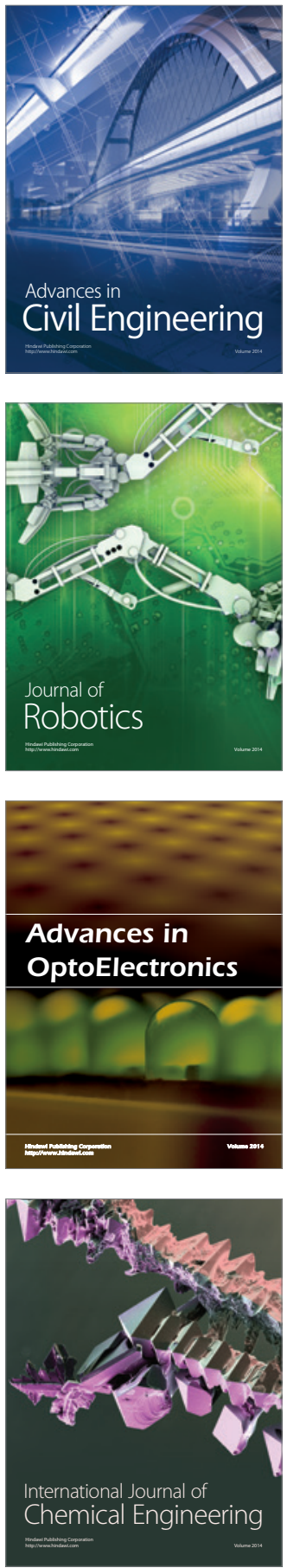

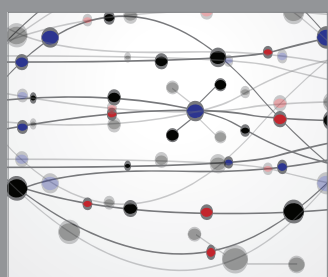

The Scientific World Journal

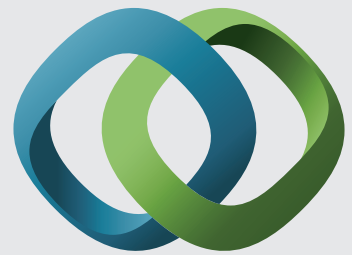

\section{Hindawi}

Submit your manuscripts at

http://www.hindawi.com
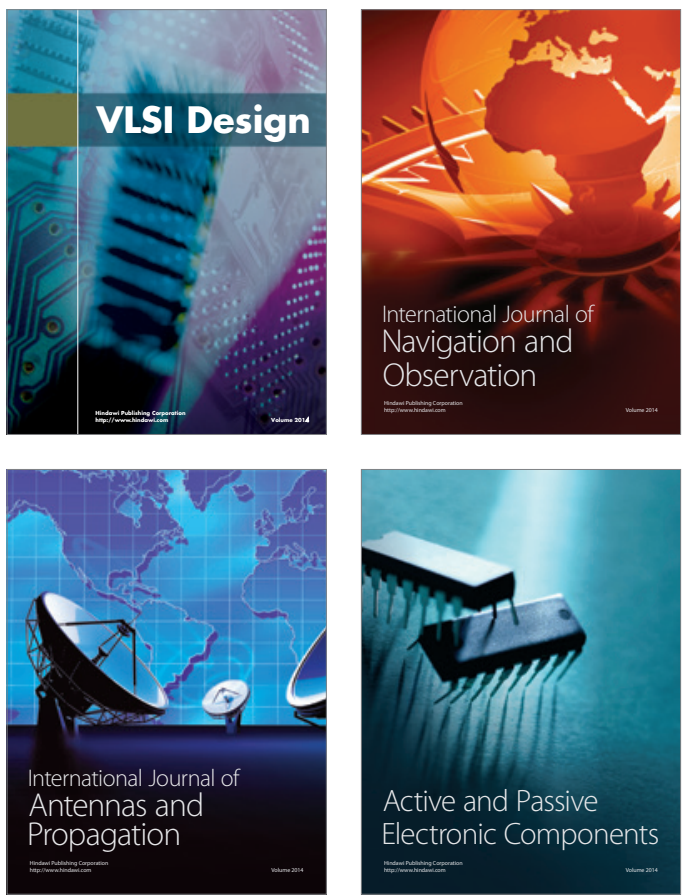
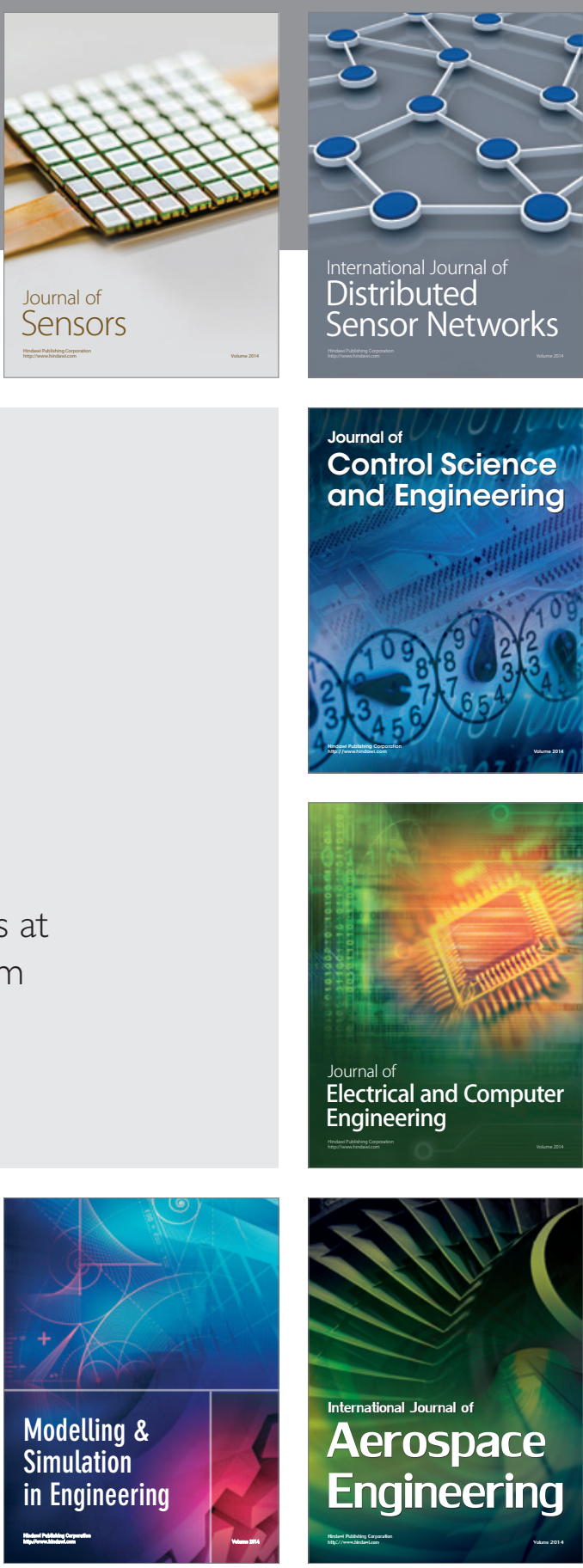

International Journal of

Distributed

Sensor Networks

Journal of

Control Science

and Engineering
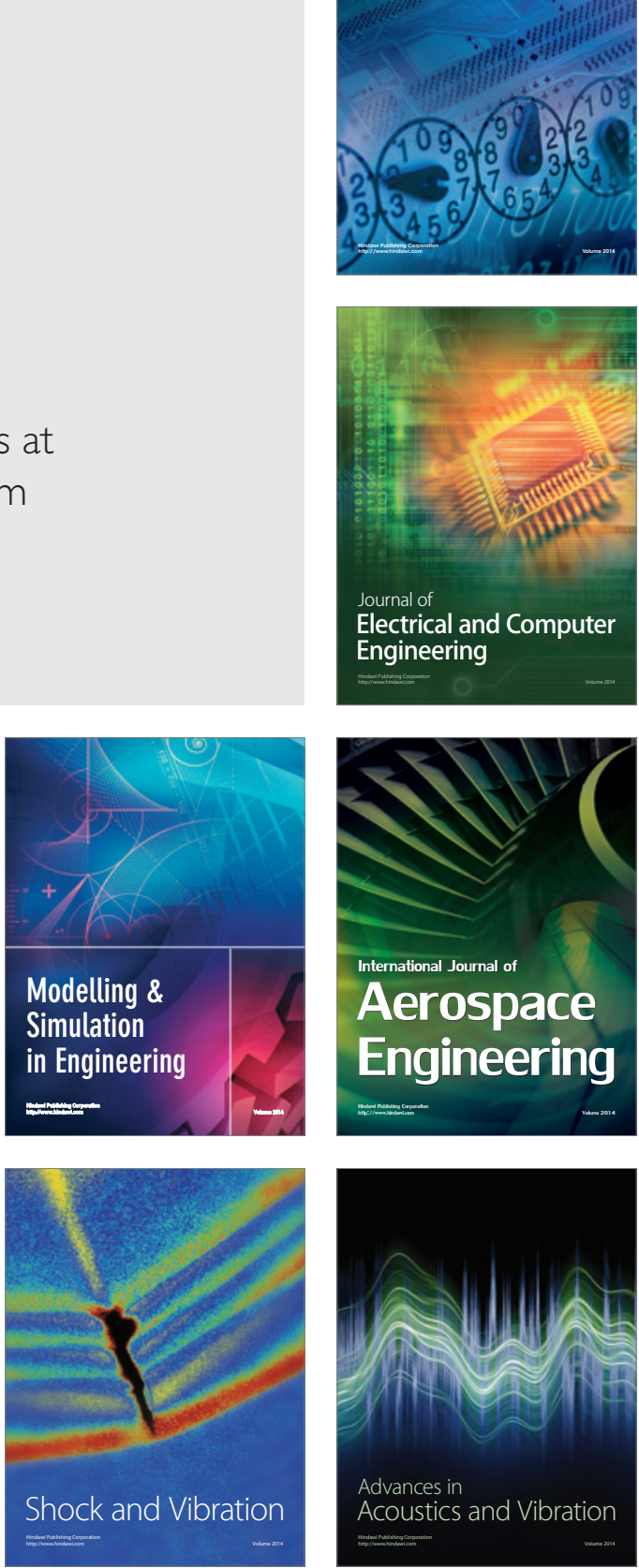